\title{
Health-related quality of life in rural children living in four European countries: the GABRIEL study
}

\author{
Laura Stöcklin · Georg Loss • Erika von Mutius • Juliane Weber · Jon Genuneit • \\ Elisabeth Horak • Barbara Sozanska $\cdot$ Hanna Danielewicz $\cdot$ Paul Cullinan · Dick Heederick · \\ Charlotte Braun-Fahrländer · and the GABRIEL study group
}

Received: 22 December 2011/Revised: 6 September 2012/Accepted: 6 September 2012/Published online: 20 December 2012

(C) Swiss School of Public Health 2012

\begin{abstract}
Objective Measuring children's health-related quality of life (HRQOL) is of growing importance given increasing chronic diseases. By integrating HRQOL questions into the European GABRIEL study, we assessed differences in HRQOL between rural farm and non-farm children from Germany, Austria, Switzerland and Poland to relate it to common childhood health problems and to compare it to a representative, mostly urban German population sample (KIGGS).

Methods The parents of 10,400 school-aged children answered comprehensive questionnaires including health-related questions and the KINDL-R questions assessing HRQOL.

Results Austrian children reported highest KINDL-R scores (mean: 80.9; $95 \%$ CI [80.4, 81.4]) and Polish children the lowest $(74.5 ;[73.9,75.0])$. Farm children reported higher KINDL-R scores than non-farm children $(p=0.002)$. Significantly lower scores were observed in children with allergic diseases $(p<0.001)$, with sleeping difficulties $(p<0.001)$ and in overweight children $(p=0.04)$. The
\end{abstract}

L. Stöcklin · G. Loss · C. Braun-Fahrländer ( ()

Swiss Tropical and Public Health Institute, Socinstrasse 57, P.O. Box 4002, Basel, Switzerland

e-mail: c.braun@unibas.ch

L. Stöcklin

e-mail: laura.stoecklin@gmail.ch

L. Stöcklin · G. Loss · C. Braun-Fahrländer

University of Basel, Basel, Switzerland

E. von Mutius $\cdot$ J. Weber

University Children's Hospital, LMU Munich, Munich,

Germany

J. Genuneit

Institute of Epidemiology and Medical Biometry, University of

Ulm, Ulm, Germany
German GABRIEL sample reported higher mean scores (age 7-10 years: 80.1, [79.9, 80.4]; age 11-13 years: 77.1, [74.9, 79.2]) compared to the urban KIGGS study (age 7-10 years: 79.0, [78.7-79.3]; age 11-13 years: 75.1 [74.6-75.6]). Sociodemographic or health-related factors could not explain differences in HRQOL between countries.

Conclusions Future increases in chronic diseases may negatively impact children's HRQOL.

Keywords Health-related quality of life .

Rural population - Common childhood diseases .

Allergic diseases - KINDL-R questionnaire ·

GABRIEL study

\section{Introduction}

Health-related quality of life (HRQOL) in children has become increasingly important to evaluate the well-being and functioning of child populations given the reported

\footnotetext{
E. Horak

Division of Cardiology and Pulmonology, The Department of Pediatrics and Adolescents, Innsbruck, Austria

B. Sozanska · H. Danielewicz

1st Department of Paediatrics, Allergology and Cardiology,

Wroclaw Medical University, Wroclaw, Poland

P. Cullinan

National Heart and Lung Institute, Imperial College London,

London, UK

D. Heederick

Institute for Risk Assessment Sciences (IRAS), Utrecht

University, Utrecht, The Netherlands
} 
increase in chronic diseases such as asthma and allergies or the rise in childhood obesity (Eder et al. 2006; WHO 2000). Generic and disease-specific instruments have been developed to assess HRQOL in representative population samples (The German Health Interview and Examination Survey for Children and Adolescents (KIGGS) (Erhart et al. 2007; Illi et al. 2012; Ravens-Sieberer and Bullinger 2000), Screening for and Promotion of Health-Related Quality of Life in Children and Adolescents-A European Health Perspective (KIDSCREEN) (Erhart et al. 2009; Ravens-Sieberer 2004) or in patient populations. HRQOL refers to a broad health concept and is a multifaceted construct consisting of subjective representations of physical well-being and personal well-being (WHO 2003). It can be assessed by questionnaires self-completed by youth or proxy-completed by a parenting person (Ravens-Sieberer et al. 2000). Socio-demographic factors such as age, gender, socioeconomic status and family structures as well as health-impacting conditions have been reported to influence children's HRQOL (Alvarenga and Caldeira 2009; Bradley and Corwyn 2002; Ravens-Sieberer et al. 2007). Assessment of HRQOL in European youth has so far focused on representative samples consisting of mostly urban and suburban populations (Health Behaviour in School-Aged Children (HBSC), KIDSCREEN, KIGGS) (Currie et al. 2008; Erhart et al. 2009; Ravens-Sieberer et al. 2007). In contrast, the GABRIEL study (Genuneit et al. 2011) systematically studied youth in rural environments of Germany, Austria, Switzerland and Poland. The Revised Children Quality of Life-Questionnaire (KINDL-R) (Ravens-Sieberer and Bullinger 2000) had been included into the comprehensive parental GABRIEL questionnaire offering the opportunity to study for the first time HRQOL in children growing up in a rural, partially farming environment.

The aim of the present analyses was (1) to assess differences in children's HRQOL (KINDL-R questions) according to socio-demographic factors in a rural partly farming population of four different countries, (2) to relate HRQOL to common childhood health problems such as allergic diseases, sleeping difficulties or overweight, and (3) to compare HRQOL scores of this rural sample to results of representative surveys conducted in mostly urban areas of Germany using the identical questionnaire.

\section{Methods}

Study design

The GABRIEL Advanced Survey is a cross-sectional study which was conducted in five study centres in rural areas of southern Germany (Bavaria and Baden-Württemberg), Switzerland (9 German-speaking cantons), Austria (Tyrol) and Poland (lower Silesia) between summer 2006 and spring 2008. It aimed at identifying factors underlying the protective effects of farming on asthma, allergic diseases and atopic sensitization. The design of the study has been described in detail before (Genuneit et al. 2011).

In brief, a short recruiting questionnaire was distributed through elementary schools to parents of all 6- to 13-yearold children in the selected study areas during the population-based Phase I (Table 1). To be eligible for Phase II, the parents had to give informed consent for blood sampling, genetic analyses and dust sampling. In addition, they had to be born in the study country and the children

Table 1 GABRIEL study population and design

\begin{tabular}{llccc}
\hline Study module & Study population & Total $N$ & Non-farm children $N$ & Farm children $N$ \\
\hline Phase I & General population & $103,219^{\mathrm{a}}$ & 86,640 & 16,579 \\
& Eligible for Phase II & $44,166^{\mathrm{b}}$ & 36,947 & 7,219 \\
Phase II & Exposure stratified subsample & $13,619^{\mathrm{c}}$ & 8,336 & 5,283 \\
& Questionnaire & $10,923^{\mathrm{d}}$ & 6,572 & 4,351 \\
& KINDL-R questions & $10,400^{\mathrm{e}}$ & 6,335 & 4,065 \\
& IgE measures & $10,041^{\mathrm{f}}$ & 6,032 & 4,009 \\
\end{tabular}

The GABRIEL study included Germany, Austria, Switzerland and Poland, and was conducted from 2006 to 2008

a Completed Phase I recruiting questionnaire

${ }^{\mathrm{b}}$ Eligible if children had the nationality of their study country and if their parents were born in the study country and gave consent to blood samples, genetic analyses and dust samples

${ }^{c}$ Random selection stratified for exposure

d Completed Phase II questionnaire

${ }^{\text {e }}$ Questionnaires returning $>70 \%$ valid KINDL-R questions included in our analysis

${ }^{\mathrm{f}} \mathrm{IgE}$ measures of children included in our analysis 
had to have their study country's nationality. For phase II, a disproportionate stratified random sample of 13,619 children (9,668 German-speaking and 3,951 Polish children), including a higher proportion of children with contact to farming, was selected from 44,166 eligible participants to ensure a large enough proportion of exposure to farming. A total of 10,923 parental questionnaires $(80.2 \%)$ were returned, of which 10,400 (76.4\%) had valid KINDL-R questions (see below). 10,041 children (73.7\%) provided blood samples for specific IgE determination (RAST) and had height and weight measured.

Consenting to participate in phase II was related to familial allergy, high parental education, child's allergies and to a lesser extent to exposure to farming environments, but did not bias the association between farming and allergy risk (Genuneit).

In all centres, the ethics committees of the respective universities and the data protection authorities had approved the study.

\section{Parental questionnaire}

\section{KINDL-R questions}

The KINDL-R questions about HRQOL (version for parents of children between 8 and 16 years) consist of 24 fivepoint Likert-scaled questions covering six dimensions of HRQOL: physical well-being, emotional well-being, selfesteem, family, friends and everyday functioning. All questions referred to the previous 2 weeks. To measure physical well-being, the KINDL-R questionnaire asked whether the child felt ill, had a headache or tummy-ache, felt tired and worn out or felt strong and full of energy. To measure emotional well-being, we asked if the child had fun and laughed a lot, did not feel much like doing anything, felt alone or felt scared and unsure of himself. To measure self-esteem, we asked if the child was proud of himself, felt on top of the world, felt pleased with himself or had a lot of good ideas. To measure the family wellbeing, we asked if the child got along well with the parents, if the child felt fine at home, if they quarrelled at home or if the child felt that the parent was bossing him around. To measure the friend's well-being, we asked if the child did things together with friends, was liked by other kids, got along well with friends or felt different from other children. To measure everyday functioning, we asked if the child easily coped with schoolwork, enjoyed school lessons, was worried about the future or was afraid of bad marks and grades.

The KINDL-R questions developed originally in German were translated into Polish and back-translated into German to be used in the Polish GABRIEL questionnaire.
Data were treated according to the KINDL-R manual (Ravens-Sieberer and Bullinger 2000). All questionnaires returning more than $70 \%$ valid answers to the KINDL-R questions were included in the analysis and missing answers were replaced by the individual mean value of the children as required by the KINDL-R manual. The six sub-scores consisting of four questions each were summarized to a total score. All scores were transformed to a 100-point scale. A higher score value represented a higher HRQOL.

\section{Definition of variables}

Socio-demographic factors assessed by questionnaire Information about socio-demographic factors was derived from the parental questionnaires.

Children living on a farm, currently run by their parents or by other relatives, were classified as farm children. Parental education was classified as 'high' if either of the parents had completed an education qualifying for university entrance that was contrasted to all other educational levels. The variability in school systems between the study centres necessitated this broad categorization. Other sociodemographic factors included in the analyses were sex and age of the children, number of siblings, number of adults living in the household and the person who completed the questionnaire (mother only, farther only, both of them or someone else).

Health-related problems assessed by questionnaire Asthma was defined as either wheeze in the past 12 months, or asthma inhaler use ever, or a doctor's diagnosis of asthma at least once, or of wheezy bronchitis more than once. Hay fever was defined as either nasal symptoms with itchy or watery eyes in the past 12 months or a doctor's diagnosis of hay fever ever. Atopic dermatitis was defined as a doctor's diagnosis ever. A family history of allergies was assumed when the parents or siblings were reported to have asthma, allergic rhinitis or atopic dermatitis. Sleeping difficulties were subdivided into difficulties in falling asleep (i), difficulties in sleeping through the night (ii), having both (iii) or having other sleeping difficulties (iv).

Health-related factors assessed by measurements Blood samples were collected and weight and height of the children were measured by study nurses during a school visit. Atopic sensitization was defined as specific IgE antibodies in blood samples of at least $0.7 \mathrm{kU} / \mathrm{l}$ against $D$. pteronyssinus, cat, birch or at least $0.35 \mathrm{kU} / \mathrm{l}$ against grass mix.

Children's weight and height were measured according to WHO guidelines. Children were categorized as normal weight, overweight and obese using the recommended body mass index (BMI) cutoff points (Cole et al. 2000). 
Statistical analyses

All statistical analyses were performed with STATA/IC 11.0 software for Windows (StataCorp, College Station, Tex); a $p$ value lower than 0.05 was considered significant. The stratification of the study sample was taken into account by using fixed weights (weighted up to the 44,166 participations eligible for phase II).

Analyses were limited to children aged 6-13 years, thus excluding 27 younger or older children. To assess the internal consistency of the KINDL-R questionnaire, in our survey we calculated Cronbach's alpha assuming an alpha higher than 0.7 to be appropriate (Nunnally 1994). In addition, the completeness of the answers and the distribution of the score values were analysed to exclude a ceiling or floor effect (Nunnally 1994).

We first analysed the KINDL-R-scores by comparing the crude mean values of the total score and of the sub-scores across the five study centres using univariable regression analysis. To analyse the association between the KINDL-R score and socio-demographic factors, we performed weighted bivariate and mutually adjusted multivariable regressions. Sex, age, parent's education, number of siblings, number of adults living in the household and the person completing the questionnaire were evaluated as socio-demographic factors.

Next, the association between health-related outcomes and total HRQOL and sub-scores, respectively, were studied adjusting for socio-demographic factors. Overweight, allergic diseases and sleeping difficulties were evaluated as health-related factors. The allergy outcomes were analysed in two ways, first we compared HRQOL in children with and without an allergic disease (yes/no asthma, hay fever or atopic dermatitis). As children often suffered from more than one of these diseases, we then contrasted HRQOL in children without any of the allergic diseases to the scores in children with only asthma, only hay fever, only atopic dermatitis or more than one allergic disease, respectively. In addition to socio-demographic variables, all models including allergic diseases were also controlled for sleeping difficulties, BMI, atopic sensitization and family history of atopy.

The association between HRQOL and sleeping difficulties was first adjusted for socio-demographic variables only and then additionally for allergic diseases and overweight. Similar analyses were run for the association of overweight and HRQOL.

Finally, the HRQOL scores of the rural GABRIEL sample were compared to the published scores of the representative German population sample of the KIGGS study (KIGGS study score means and 95 \% CI: age 7-10 years: 79.0, [78.7-79.3]; age 11-13 years: 75.1 [74.6-75.6]) (Ravens-Sieberer et al. 2007). The analyses were stratified by age group to directly compare them to the KIGGS study. This final analysis was restricted to the 4,156 children aged 7-10 years and the 69 children aged 11-13 years of the two German study centres.

\section{Results}

Our analyses included 8,256 German-speaking children (2,271 in Baden-Württemberg, 2,203 in Bavaria, 1,631 in Austria, 2,154 in Switzerland) and 2,141 Polish children.

In all five study centres, consistency in answering the questionnaire was high with Cronbach's alphas above 0.84 in all centres. The German-speaking study centres had a high rate of completion, returning only $137(1.6 \%)$ invalid questionnaires. In the Polish sample, 386 (15.3\%) invalid questionnaires were returned, which were more likely to be from farming families $(p<0.001)$ or from families with lower parental education level $(p<0.001)$, though farming and parental education were independent from each other. The total score means were normally distributed showing no ceiling or floor effect.

HRQOL and socio-demographic factors

In bivariate (unadjusted) analyses, KINDL-R scores were associated with several of the tested socio-demographic factors (Table 2). In analyses mutually adjusting for all listed socio-demographic variables, higher scores were reported for girls compared to boys ( $p=0.01)$, for younger children $(p<0.001)$, for farm children $(p=0.01)$, when parents had a high education level $(p<0.001)$, and when both parents filled in the questionnaire $(p<0.001)$. There was no association with the number of adults living in the household or with the number of siblings.

Sub-scores of farm and non-farm children mostly differed for physical well-being which was higher in farm children (Fig. 1).

HRQOL and health-related factors

Health-related factors were strongly associated with KINDL-R scores (Table 3). In analyses adjusting for sociodemographic factors, lower total scores were reported for children suffering from asthma $(p<0.001)$, hay fever $(p<0.001)$ or atopic dermatitis $(p<0.01)$. When simultaneously adjusting for family history of allergic diseases, atopy, sleeping difficulties and overweight, the association between HRQOL and all three allergy outcomes was attenuated, whereas the association with sleeping difficulties remained strong (Table 3). Inclusion of overweight only attenuated the association between HRQOL and 
Table 2 Socio-demographic factors and their association with total health-related quality of life (KINDL-R scores)

\begin{tabular}{|c|c|c|c|c|c|c|c|c|}
\hline & \multicolumn{2}{|c|}{ Distribution } & \multicolumn{2}{|c|}{ Score means } & \multicolumn{2}{|c|}{ Unadjusted association } & \multicolumn{2}{|c|}{ Mutually adjusted } \\
\hline & $n$ & $\%$ & Mean & $95 \% \mathrm{CI}$ & Beta-coeff. & $p$ value & Beta-coeff. & $p$ value \\
\hline \multicolumn{9}{|l|}{ Sex } \\
\hline Boys & 5,214 & 50.1 & 79.1 & $(78.8-79.4)$ & Ref. & & Ref. & \\
\hline Girls & 5,186 & 49.9 & 79.6 & $(79.3-79.9)$ & 0.5 & 0.04 & 0.61 & 0.01 \\
\hline \multicolumn{9}{|l|}{ Age } \\
\hline Aged $11-13$ years & 1,708 & 16.6 & 76.4 & $(75.8-77.0)$ & Ref. & & Ref. & \\
\hline Aged 7-10 years & 8,242 & 80.3 & 79.7 & $(79.4-80.0)$ & 3.3 & $<0.001$ & 2.08 & $<0.001$ \\
\hline Aged 6 & 313 & 3.1 & 81.3 & $(80.0-82.2)$ & 4.88 & $<0.001$ & 3.16 & $<0.001$ \\
\hline \multicolumn{9}{|l|}{ Farming } \\
\hline Non-farmers & 6,335 & 60.9 & 79.4 & $(79.1-79.7)$ & Ref. & & Ref. & \\
\hline Farmers & 4,065 & 39.1 & 79.2 & $(78.9-79.5)$ & -0.17 & 0.41 & 0.62 & 0.01 \\
\hline \multicolumn{9}{|l|}{ Education level } \\
\hline Low education level & 7,349 & 73.1 & 79.2 & $(79.0-79.5)$ & Ref. & & Ref. & \\
\hline High education level & 2,704 & 26.9 & 79.6 & $(79.2-80.1)$ & 0.38 & 0.15 & 1.13 & $<0.001$ \\
\hline \multicolumn{9}{|l|}{ Number of siblings } \\
\hline 1 sibling & 4,305 & 41.7 & 78.7 & $(77.8-79.5)$ & Ref. & & Ref. & \\
\hline No siblings & 761 & 7.4 & 79.6 & $(79.3-80.0)$ & -0.97 & 0.03 & -0.4 & 0.4 \\
\hline 2 siblings & 3,229 & 31.2 & 79.3 & $(79.0-79.7)$ & -0.32 & 0.25 & -0.28 & 0.34 \\
\hline$>2$ siblings & 2,037 & 19.7 & 79.2 & $(78.6-79.8)$ & -0.44 & 0.21 & -0.12 & 0.74 \\
\hline \multicolumn{9}{|c|}{ Number of adults living in the household } \\
\hline 2 adults & 7,509 & 72.9 & 79.6 & $(79.4-79.9)$ & Ref. & & Ref. & \\
\hline 1 adult & 386 & 3.7 & 78.2 & $(77.1-79.3)$ & -1.46 & 0.01 & -0.81 & 0.16 \\
\hline$>2$ adults & 2,410 & 23.4 & 78.5 & $(78.0-79.0)$ & -1.17 & $<0.001$ & -0.13 & 0.69 \\
\hline \multicolumn{9}{|l|}{ Questionnaire answered by } \\
\hline Answ by mother & 8,214 & 81.1 & 79 & $(78.8-79.3)$ & Ref. & & Ref. & \\
\hline Answ by father & 233 & 2.3 & 78.4 & $(76.8-80.0)$ & -0.61 & 0.45 & -0.36 & 0.67 \\
\hline Answ by father and mother & 1,645 & 16.2 & 81.1 & $(80.6-81.7)$ & 2.09 & $<0.001$ & 1.8 & $<0.001$ \\
\hline Answ by others & 37 & 0.4 & 73.8 & $(71.3-76.4)$ & -5.19 & $<0.001$ & -2.41 & 0.06 \\
\hline \multicolumn{9}{|l|}{ Study centre } \\
\hline Baden-Württemberg (Germany) & 2,271 & 21.8 & 79.8 & $(79.4-80.3)$ & Ref. & & Ref. & \\
\hline Bavaria (Germany) & 2,203 & 21.2 & 79.7 & $(79.2-80.2)$ & -0.16 & 0.64 & 0.06 & 0.85 \\
\hline Austria & 1,631 & 15.7 & 80.9 & $(80.4-81.4)$ & 1.05 & $<0.01$ & 1.09 & $<0.01$ \\
\hline Switzerland & 2,151 & 20.7 & 79.7 & $(79.2-80.1)$ & -0.15 & 0.64 & 0.8 & 0.03 \\
\hline Poland & 2,141 & 20.6 & 74.5 & $(73.9-75.0)$ & -5.38 & $<0.001$ & -4.76 & $<0.001$ \\
\hline
\end{tabular}

The GABRIEL study included Germany, Austria, Switzerland and Poland, and was conducted from 2006 to 2008

Beta-coeff. beta-coefficient, $n$ number in study population, Ref. reference

asthma as both variables were significantly associated. Total and sub-score means were clearly lower in children suffering from one allergic disease compared to children with no allergic disease, but the lowest values were observed for children whose parents reported having more than one allergic disease (Fig. 2, panel A), especially for the sub-score of physical well-being.

The health problems most strongly associated with HRQOL were sleeping difficulties $(p<0.001)$. Children who reported having both difficulties in falling asleep and difficulties in sleeping through the night had the lowest score means (Table 3). When evaluating the six sub-scores, the strongest inverse associations were found between sleeping difficulties and the dimensions 'physical wellbeing', 'self-esteem' and 'everyday functioning' (Fig. 2, panel B).

Lower total score means were also found in overweight $(p=0.04)$ and obese children $(p=0.01)$ indicating a dose-response pattern with increasing overweight (Fig. 2, panel C). 


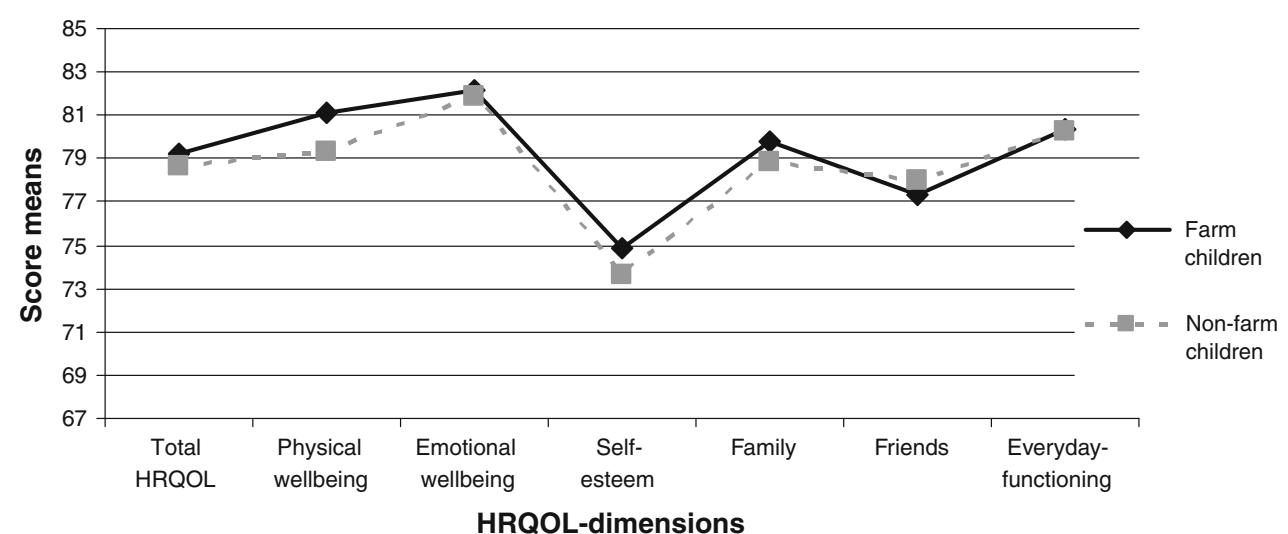

Fig. 1 Adjusted total and sub-score means of health-related quality of life (KINDL-R) according to farming (GABRIEL-Study). The GABRIEL study included Germany, Austria, Switzerland and Poland, and was conducted from 2006 to 2008. Means adjusted for farming,

\section{Centre differences}

We found significantly higher KINDL-R score means in all German-speaking study centres compared to Poland. The highest score means of the German-speaking study centres were reported for Austrian children (Table 2; Fig. 3).

Centre differences in HRQOL scores remained when adjusted for socio-demographic variables, but there was no difference between the two German study centres (Table 2). When comparing the adjusted sub-scores across study centres, the pattern was similar in the Germanspeaking centres with the lowest sub-score means for selfesteem and friends. In Poland, sub-scores were lower than in the German-speaking study centres and showed a different pattern with the lowest sub-scores for physical wellbeing and everyday functioning (Fig. 3, panel B).

The associations between HRQOL and health problems were consistent across all study centres. No significant interaction of any of the interesting variables with study centre was observed.

\section{Comparison to the KIGGS sample}

When KINDL-R score means of the rural German GABRIEL sample were compared to the representative German KIGGS sample (Ravens-Sieberer et al. 2007), higher score means were observed in the rural GABRIEL sample (score means and $95 \% \mathrm{CI}$ age $7-10$ years: 80.1, [79.9, 80.4]; age 11-13 years: 77.1, $[74.9,79.2]$ than in the KIGGS survey (age 7-10 years: 79.0, [78.7-79.3]; age 11-13 years: 75.1 [74.6-75.6]) (Fig. 4). Significant differences were found for the dimensions 'physical well-being' and 'self-esteem' in both age groups, but were more pronounced for the older children (Fig. 4). socio-demographic variables (age, sex, parental education, number of siblings, number of adults living in household, person completing the questionnaire) and study centres

\section{Discussion}

This large survey of children living in rural areas of Germany, Austria, Switzerland and Poland showed significant differences in HRQOL across countries and indicated higher scores for children living in rural areas compared to the representative sample of the KIGGS study. Children suffering from sleeping difficulties or allergic diseases and overweight children reported significantly lower HRQOL score means suggesting that these common health problems impacted the well-being of children.

Although the differences in KINDL-R score means were found to be small, they were in the same range as reported by others (Ravens-Sieberer et al. 2007). As they represent differences in population score means, a small shift in the distribution of the scores between two groups may result in larger individual deviations.

The observed differences in children's HRQOL across European countries are consistent with previous European studies (Erhart et al. 2009; Michel et al. 2009; PetersenEwert et al. 2011; Ravens-Sieberer et al. 2008; UNICEF 2007) and were not due to country differences in sociodemographic factors or disease prevalence. The internal consistency of the questionnaires (measured by Cronbach's alpha) was high in all five study centres and thus does not explain the differences. The higher rate of non-valid questionnaires in Poland tended to be from families with lower educational background and from farming families and might be linked to the lengths of the comprehensive GABRIEL questionnaire. As lower educational background and farming had opposed associations with HRQOL in our samples, it is unlikely that the exclusion of these children markedly influenced the overall assessment of HRQOL scores in Poland. We consider these country differences to be real and to reflect the subjective well- 
Table 3 Association between health-related factors and total health-related quality of life (KINDL-R scores)

\begin{tabular}{|c|c|c|c|c|c|c|c|c|}
\hline & \multicolumn{2}{|c|}{ Distribution } & \multicolumn{2}{|c|}{ Score means } & \multicolumn{2}{|c|}{$\begin{array}{l}\text { Association adjusted } \\
\text { for socio-demographic } \\
\text { factors }^{\mathrm{a}}\end{array}$} & \multicolumn{2}{|c|}{$\begin{array}{l}\text { Association additionally } \\
\text { adjusted for health-related } \\
\text { factors }^{\mathrm{b}}\end{array}$} \\
\hline & $n$ & $\%$ & Mean & $95 \% \mathrm{CI}$ & Beta-coeff. & $p$ value & Beta-coeff. & $p$ value \\
\hline \multicolumn{9}{|l|}{ Allergic diseases } \\
\hline No asthma & 7,923 & 76.22 & 80 & $(79.8-80.1)$ & Ref & & Ref & \\
\hline Any asthma & 2,472 & 23.78 & 77.1 & $(76.6-77.6)$ & -2.23 & $<0.001$ & -1.23 & $<0.001$ \\
\hline No hay fever & 8,760 & 84.41 & 79.8 & $(79.6-80.1)$ & Ref & & Ref & \\
\hline Any hay fever & 1,618 & 15.59 & 77.1 & $(76.5-77.7)$ & -2.22 & $<0.001$ & -1.64 & $<0.001$ \\
\hline No eczema & 8,600 & 83.58 & 79.7 & $(79.5-80.0)$ & Ref & & Ref & \\
\hline Any eczema & 1,689 & 16.42 & 77.7 & $(77.2-78.3)$ & -1.87 & $<0.001$ & -1.06 & $<0.01$ \\
\hline \multicolumn{9}{|l|}{ Frequency of allergic diseases } \\
\hline No allergic disease & 6,639 & 63.86 & 80.3 & $(80.0-80.6)$ & Ref & & Ref & \\
\hline Only asthma & 1,496 & 14.39 & 77.7 & $(77.1-78.4)$ & -1.97 & $<0.001$ & -1.45 & $<0.001$ \\
\hline Only hay fever & 261 & 2.51 & 78.6 & $(77.1-80.2)$ & -2 & 0.02 & -1.95 & 0.03 \\
\hline Only atopic dermatitis & 901 & 8.67 & 78.8 & $(78.1-79.6)$ & -1.38 & $<0.01$ & -1.05 & 0.02 \\
\hline More than 2 allergic diseases & 1,099 & 10.57 & 76.6 & $(75.9-77.4)$ & -3.2 & $<0.001$ & -2.68 & $<0.001$ \\
\hline \multicolumn{9}{|l|}{ Sleeping difficulties } \\
\hline No sleeping difficulties & 7,854 & 77.52 & 80.6 & $(80.4-80.9)$ & Ref & & Ref & \\
\hline Diff in falling asleep & 1,791 & 17.68 & 75.6 & $(75.0-76.2)$ & -5.06 & $<0.001$ & -5.12 & $<0.001$ \\
\hline Diff in sleeping through & 241 & 2.38 & 76.9 & $(75.2-76.2)$ & -4.18 & $<0.001$ & -4.27 & $<0.001$ \\
\hline Diff in falling asleep and sleeping through & 213 & 2.1 & 70.9 & $(69.1-72.6)$ & -9.56 & $<0.001$ & -9.52 & $<0.001$ \\
\hline Other sleeping difficulties & 32 & 0.32 & 74.6 & $(70.2-78.9)$ & -5.36 & 0.01 & -4.64 & 0.02 \\
\hline \multicolumn{9}{|l|}{ Body mass index } \\
\hline Normal weight children & 8,204 & 81.37 & 79.7 & $(79.4-79.9)$ & Ref & & Ref & \\
\hline Overweight children & 1,431 & 14.19 & 78.3 & $(77.7-78.9)$ & -0.81 & 0.02 & -0.7 & 0.04 \\
\hline Obese children & 447 & 4.43 & 77.4 & $(76.1-78.7)$ & -1.49 & 0.03 & -1.76 & 0.01 \\
\hline
\end{tabular}

The GABRIEL study included Germany, Austria, Switzerland and Poland, and was conducted from 2006 to 2008

Sleeping difficulties and BMI adjusted for socio-demographic and health-related factors (allergic diseases, sleeping difficulties, BMI) not including atopy and family history for allergies

Beta-coeff. beta-coefficient, $n$ number in study population, Ref. reference

a Adjusted for socio-demographic factors (age, sex, farming, parental education, number of siblings, number of adults living in household, person completing the questionnaire)

b Allergic diseases and frequency of allergies adjusted for socio-demographic factors and health-related factors (atopy, family history for allergies, sleeping difficulties and BMI)

being of children, which needs to be interpreted in the sociocultural context of each country.

Age and gender differences in HRQOL as reported in the GABRIEL survey have consistently been found in several surveys (Giannakopoulos et al. 2009; Michel et al. 2009; Ravens-Sieberer et al. 2007). In contrast to others (Amato and Keith 1991; Bradley and Corwyn 2002; Eymann et al. 2009), we did not observe an association between the number of adults or children living in a household and HRQOL. It has been suggested that single parent families, implying parental absence, economic disadvantage and potential family conflicts (Amato and Keith 1991), or a high number of siblings, implying less attention from parents (Bradley and Corwyn 2002), may negatively impact HRQOL.
The results of the present study additionally illustrate that HRQOL assessment depends on the person who answered the questionnaire and we thus suggest that this aspect needs to be taken into account in future surveys.

The GABRIEL survey specifically focused on allergic diseases and the farm environment. Children suffering from asthma, hay fever and eczema reported consistently lower HRQOL scores than children without these diseases, which is in line with several previous studies (Alvarenga and Caldeira 2009; Camelo-Nunes and Solé 2010; Camfferman et al. 2010; Ravens-Sieberer et al. 2007; Silva et al. 2009). Nocturnal symptoms frequently occurring in children with asthma disturbing their sleep quality (Fagnano et al. 2011) might explain why adjustment for sleeping difficulties attenuated the association between asthma and HRQOL. As 
(A)

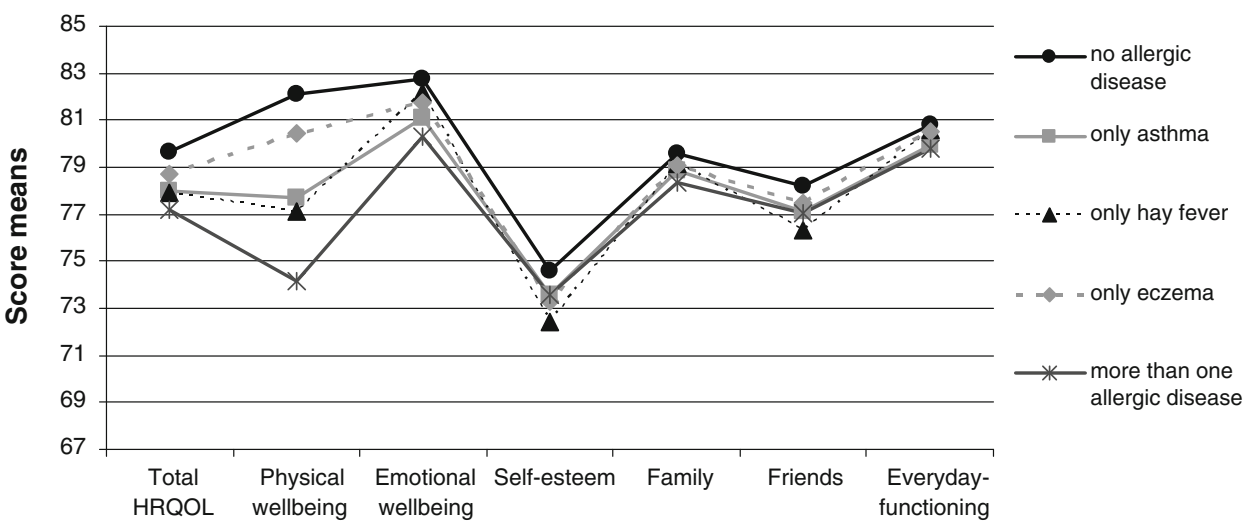

HRQOL-dimensions

(B)

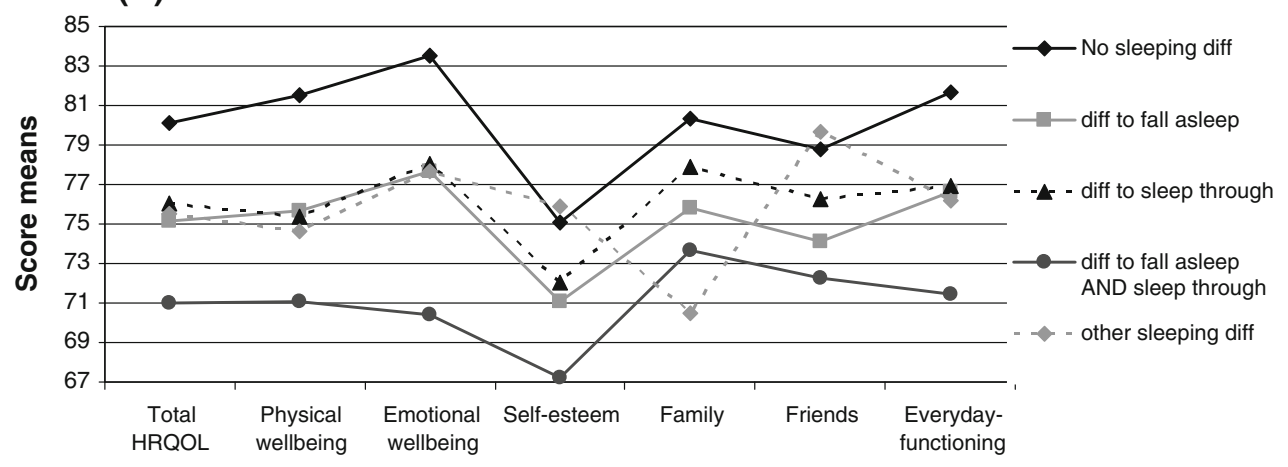

HRQOL-dimensions

(C)

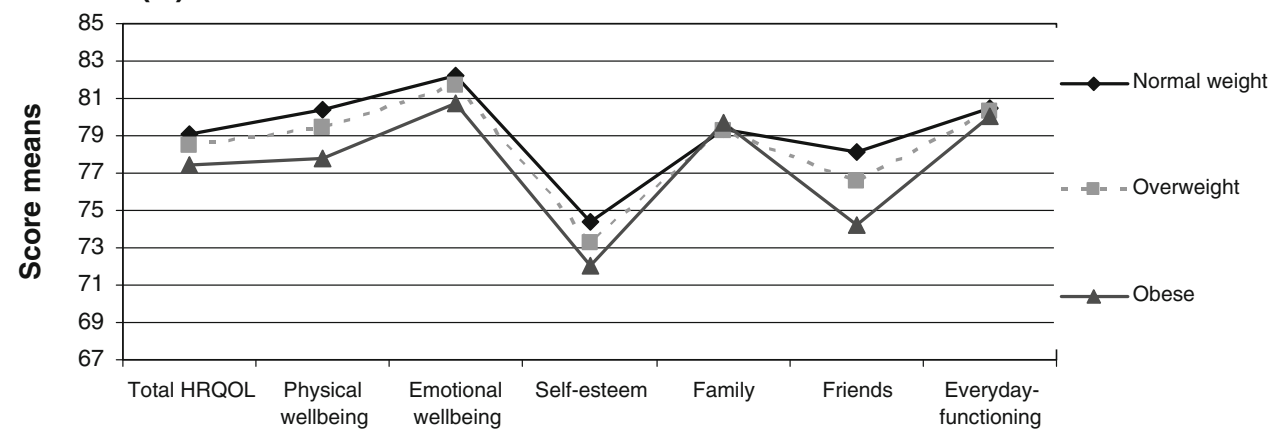

HRQOL-dimensions

Fig. 2 Adjusted total and sub-score means of health-related quality of life (KINDL-R) according to the presence of allergic diseases (a), sleeping difficulties (b) and weight category (c). The GABRIEL study included Germany, Austria, Switzerland and Poland, and was conducted from 2006 to 2008. a Means adjusted for sociodemographic variables (age, sex, farming, parental education, number of siblings, number of adults living in household, person completing

the study was cross-sectional in design, the direction of causality cannot be inferred with certainty.

The present study was sufficiently powered to evaluate the role of farm living and HRQOL. Farm children reported the questionnaire) and health-related variables (atopy, family history for atopic diseases, sleeping difficulties, weight category) and study centres. b, c Means adjusted for farming, socio-demographic variables (as described above), allergic diseases and weight category or sleeping difficulties as appropriate. $H R Q O L$ Health-related quality of life, diff difficulties

higher HRQOL than non-farm children independent of other socio-economic factors. The association between farming and HRQOL was somewhat stronger in the German-speaking countries. This might explain why the 
Fig. 3 Study centre differences of total health-related quality of life (KINDL-R) scores and subscores. The GABRIEL study included Germany, Austria, Switzerland and Poland, and was conducted from 2006 to 2008. a Total score means (95\% CI) by study centre. b Adjusted means of total score and sub-scores by study-centre. Means adjusted for farming and socio-demographic variables (age, sex, parental education, number of siblings, number of adults living in household, person completing the questionnaire). HRQOL Healthrelated quality of life

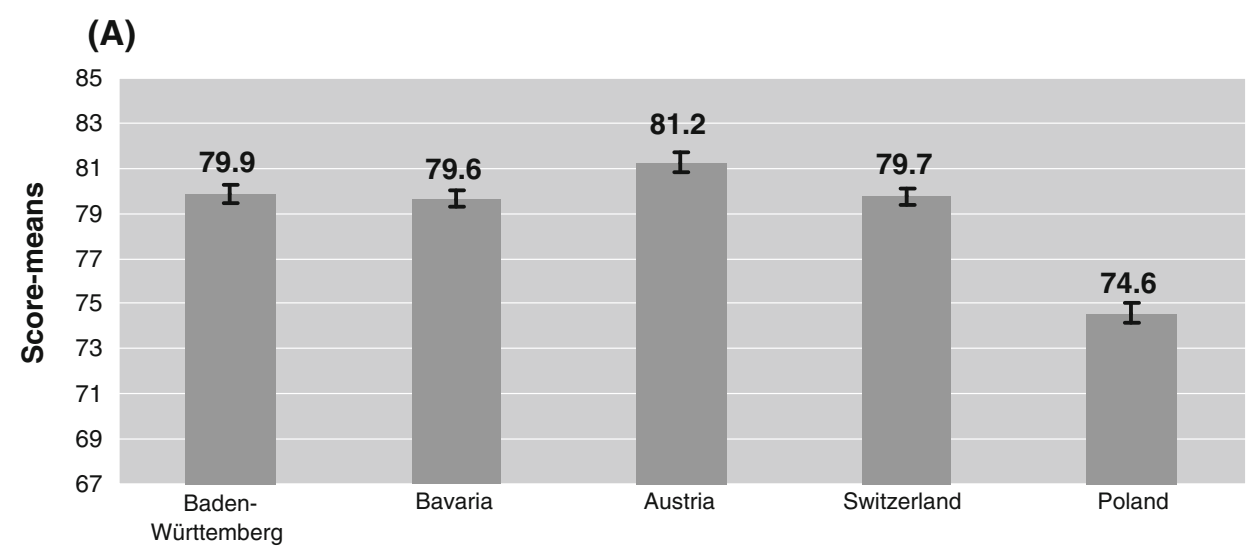

Study centres

(B)

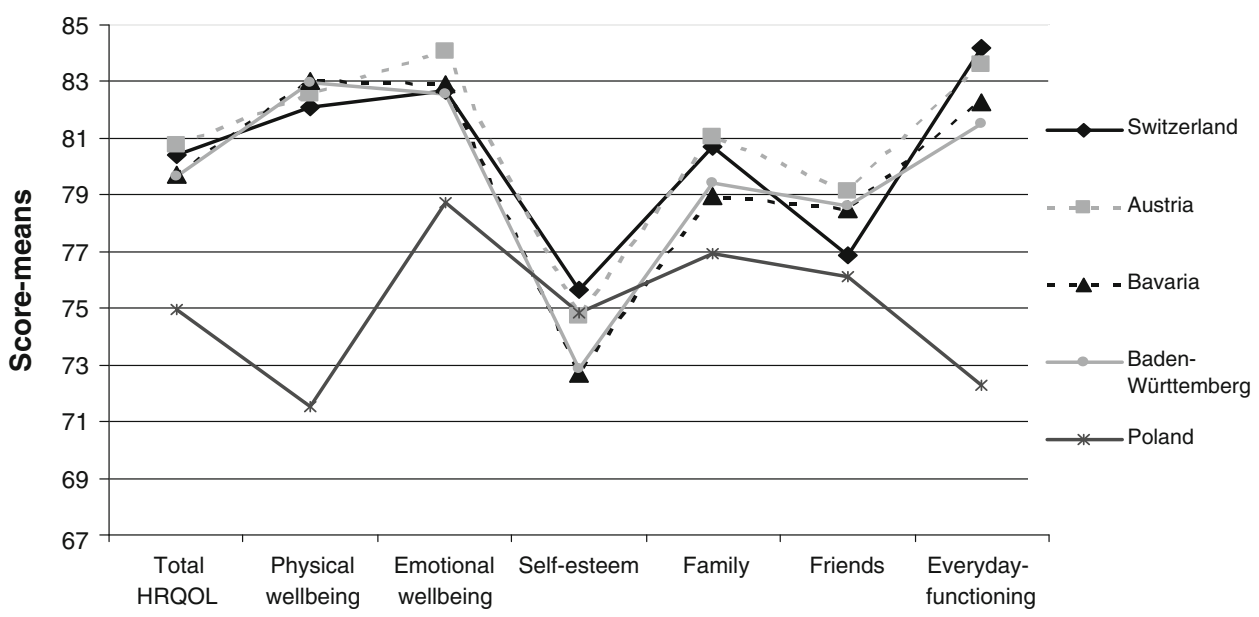

association was only significant in models taking country into account. The differences were most pronounced for the sub-dimension 'physical well-being' and might at least in part be explained by the lower prevalence of asthma and allergies among farm children (Illi et al. 2011, Illi et al. 2012; von Mutius and Vercelli 2010). HRQOL did, however, not explain the protective effect of farming on allergies (Stocklin et al. 2012).

The health problems most strongly associated with lower HRQOL were sleeping difficulties.

Poor quality of sleep may imply daytime sleepiness, fatigue and significant impairment of learning and cognition which have been related to lower optimism and selfesteem impacting HRQOL in children (Lemola et al. 2010). Additionally, sleeping difficulties are non-specific complaints associated with many physical and mental disorders (Chorney et al. 2008; Hysing et al. 2009; Luntamo et al. 2011; Sung et al. 2008) and may be an indicator of anxiety and other psychological disorders which we did not investigate in our questionnaire. As more than $20 \%$ of our study population reported sleeping difficulties, these complaints represent a relevant factor impacting childhood HRQOL.

Overweight and, even more so, obese children reported lower HRQOL than normal weight children, which is in line with earlier findings (Tsiros et al. 2009). However, a recent Norwegian study found no significant association between BMI and HRQOL, but a strong impact of bullying (Haraldstad et al. 2011). In the present survey, obese children reported significantly lower scores for the subdimension 'friends'. Obese children might be teased or otherwise bullied by other children and thus report lower HRQOL.

The German subgroup of the rural GABRIEL sample reported higher HRQOL score means than the representative German KIGGS sample. The difference might in part be due to the high proportion of farm children in the GABRIEL study reporting higher HRQOL and lower rates of allergic diseases (Illi et al. 2012). In addition, the GABRIEL sample was restricted to children having their country's nationality and thus excluding the migrant population. Ravens-Sieberer et al. (2007) have shown that 
Fig. 4 Comparison of total health-related quality of life (KINDL-R) score means and sub-score means of the German GABRIEL sample and the KIGGS sample (crude means of the KINDL-R scores of the representative German KIGGS study published by RavensSieberer et al. 2007) according to age group. The GABRIEL study included Germany, Austria, Switzerland and Poland, and was conducted from 2006 to 2008. a Children aged 7-10 years. b Children aged 11-13 years. HRQOL Healthrelated quality of life
(A)

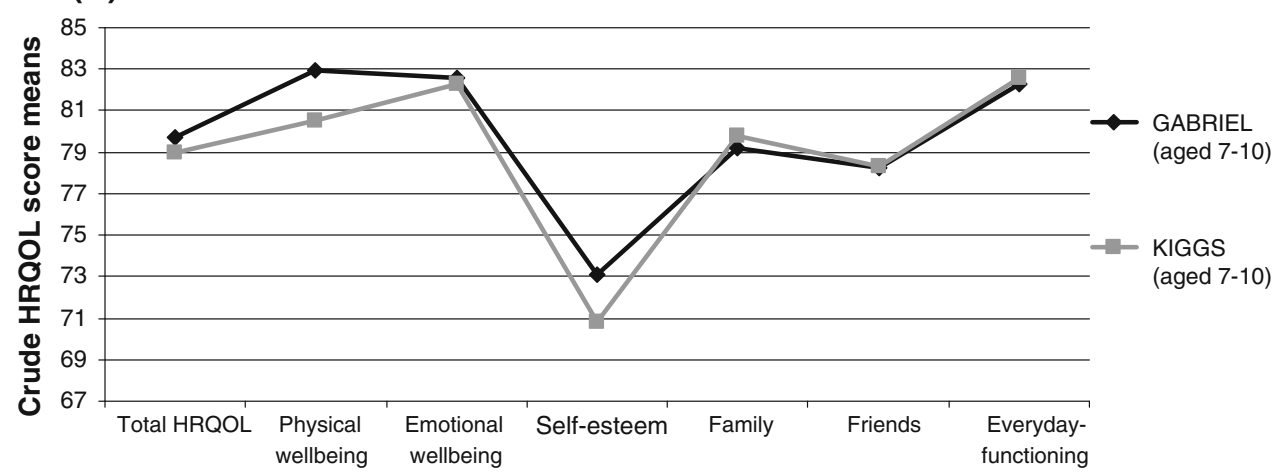

HRQOL-dimensions

(B)

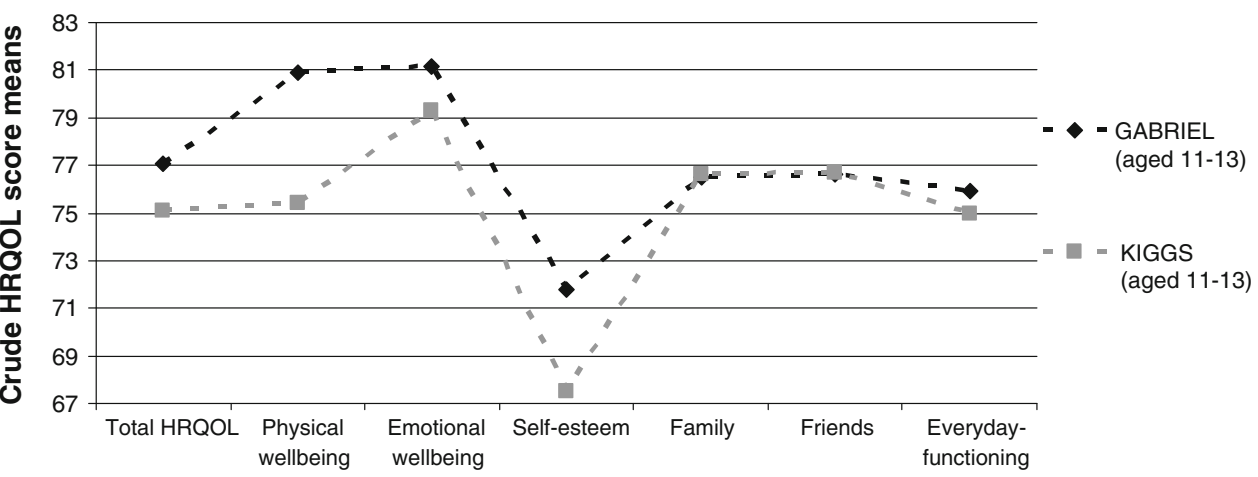

HRQOL-dimensions differences in HRQOL between migrant and indigenous children were due to socioeconomic differentials. Children from lower socioeconomic status might thus be underrepresented in the GABRIEL sample. In addition, it might be speculated that urbanization is related to HRQOL, but this hypothesis needs to be examined.

The large sample size, the careful standardization of the cross-country assessment, the focus on the rural environment and the use of a validated tool to assess HRQOL can be considered strengths of the present study. There were, however, also some weaknesses. The questionnaire lacked questions related to the child's psychological disorders or to parents' mental health which are known to negatively impact children's quality of life (Giannakopoulos et al. 2009; Ravens-Sieberer et al. 2007). In addition, residual confounding might be present as the assessment of parent's education level was only a crude proxy of socioeconomic status which, nevertheless, showed the expected association with HRQOL. As the educational systems in the four study countries differed greatly, we had to limit the differentiation to two education levels. This might be an over-simplification of the real situation. HRQOL in children was assessed exclusively using parents' reports and might represent parents' expectations rather than children's real quality of life.
The present study is the first to explicitly assess HRQOL in a rural partly farming childhood population. So far, representative samples of youth living mostly in urban and sub-urban areas have been investigated. The reported higher scores of HRQOL of the present sample might in part be explained by the lower prevalence of allergic diseases among farm children. However, they may also allude to a negative role of urbanization on children's HRQOL. Differences in HRQOL according to grade of urbanization need to be further explored and understood as populations tend to become increasingly urbanized. Country differences in HRQOL seem to be independent of urbanization and need to be further explored taking the sociocultural context of a country into account.

Acknowledgments We are grateful to Ulrike Ravens-Sieberer and the Robert Koch Institute, Berlin for sharing the KINDL-R questionnaire on health-related quality of life. This work was supported by the European Commission as part of GABRIEL (A multidisciplinary study to identify the genetic and environmental causes of asthma in the European Community), contract number 018996 under the Integrated Program LSH-2004-1.2.5-1.

Conflict of interest None of the authors had any conflict of interest. None of the authors received fees for the study. 
Ethical standards In all countries participating in our study, the ethics committees of the respective universities and the data protection authorities had approved the study.

\section{Appendix}

The members of the GABRIEL study group are in alphabetical order:

Silvia Apprich Ph.D. ${ }^{\mathrm{G}}$, Andrzej Boznanski ${ }^{\mathrm{K}}$, Gisela Büchele $\mathrm{MPH}^{\mathrm{C}}$, William Cookson M.D. D.Phil. ${ }^{\mathrm{A}}$, Anna Dębińska $^{\mathrm{K}}$, Martin Depner Ph.D. ${ }^{\mathrm{B}}$, Markus Ege M.D. ${ }^{\mathrm{B}}$, Urs Frey M.D., Ph.D. ${ }^{\mathrm{L}}$, Oliver Fuchs M.D. ${ }^{\mathrm{L}}$, Anne Hyvärinen Ph.D. ${ }^{\text {H }}$, Sabina Illi Ph.D. ${ }^{\text {B }}$, Michael Kabesch M.D. ${ }^{\mathrm{N}}$, Katalin Kovacs ${ }^{\mathrm{M}}$, Aleksandra Kosmęda Ph.D. ${ }^{\mathrm{K}}$, Wolfgang Kneifel Ph.D. ${ }^{\text {G }}$, Philipp Latzin M.D. Ph.D. ${ }^{\text {L }}$, Roger Lauener M.D. ${ }^{\text {, }}$, Stephanie MacNeill M.Sc. ${ }^{\text {A }}$, Bernhard Morass M.D. ${ }^{\mathrm{M}}$, Anne-Cécile Normand ${ }^{\mathrm{I}}$, Ilka Noss Ph.D. ${ }^{\mathrm{F}}$, Renaud

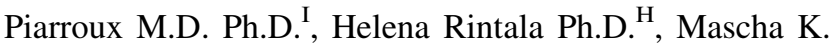
Rochat M.D. ${ }^{\mathrm{Q}}$, Nikolaos Sitaridis ${ }^{\mathrm{C}}$, David Strachan M.D. ${ }^{\text {, }}$, Christine Strunz-Lehner $\mathrm{MPH}^{\mathrm{B}}$, Bertrand Sudre M.D. Ph.D. , Marco Waser Ph.D. ${ }^{\text {D,E }}$, Inge Wouters Ph.D. ${ }^{\mathrm{F}}$

A. Imperial College London, National Heart and Lung Institute, London, United Kingdom

B. University Children's Hospital, LMU Munich, Munich, Germany

C. Ulm University, Institute of Epidemiology and Medical Biometry, Ulm, Germany

D. Swiss Tropical and Public Health Institute, Basel, Switzerland

E. University of Basel, Basel, Switzerland

F. Utrecht University, Institute for Risk Assessment Sciences (IRAS), Division of Environmental Epidemiology, Utrecht, The Netherlands

G. BOKU Vienna, University of Natural Resources and Applied Life Sciences, Department of Food Science and Technology, Vienna, Austria

H. THL Kuopio, National Institute for Health and Welfare, Kuopio, Finland

I. Université de Franche-Comté, UMR 6249 ChronoEnvironnement, Département de Parasitologie/Mycologie, UFR SMP, Besançon, France

J. Wroclaw Medical University, 1st Department of Paediatrics, Allergology and Cardiology, Wroclaw, Poland

K. Division of Pulmonology, Department of Paediatrics, Bern University Hospital, Switzerland

L. Department of Pediatrics and Adolescents, Division of Cardiology and Pulmonology, Innsbruck Medical University, Innsbruck, Austria

M. Hannover Medical School, Clinic for Paediatric Pneumology and Neonatology, Hannover, Germany

N. St George's Hospital, University of London, London, United Kingdom
O. High Mountain Hospital Davos, Davos, Switzerland

P. Département médico-chirurgical de pédiatrie, CHUV, Lausanne, Switzerland

\section{References}

Alvarenga TMM, Caldeira AP (2009) Quality of life in pediatric patients with atopic dermatitis. J Pediatria 85(5):415-420

Amato PR, Keith B (1991) Parental divorce and the well-being of children: a meta-analysis. Psychol Bull 110(1):26-46

Bradley RH, Corwyn RF (2002) Socioeconomic status and child development. Annu Rev Psychol 53:371-399

Camelo-Nunes IC, Solé D (2010) Allergic rhinitis: indicators of quality of life. Jornal Brasileiro De Pneumologia: Publicaçao Oficial Da Sociedade Brasileira De Pneumologia E Tisilogia 36(1):124-133

Camfferman D, Kennedy JD, Gold M, Martin AJ, Lushington K (2010) Eczema and sleep and its relationship to daytime functioning in children. Sleep Med Rev 14(6):359-369

Chorney DB, Detweiler MF, Morris TL, Kuhn BR (2008) The interplay of sleep disturbance, anxiety, and depression in children. J Pediatr Psychol 33(4):339-348. doi:10.1093/jpepsy/ jsm105

Cole TJ, Bellizzi MC, Flegal KM, Dietz WH (2000) Establishing a standard definition for child overweight and obesity worldwide: international survey. BMJ 320(7244):1240-1243

Currie $C$ et al (2008) Inequalities in young people's health (HBSC). http://wwwhbscorg/. Accessed 12.12.2011 2011

Eder W et al (2006) Association between exposure to farming, allergies and genetic variation in CARD4/NOD1. Allergy 61(9):1117-1124. doi:10.1111/j.1398-9995.2006.01128.x

Erhart M, Holling H, Bettge S, Ravens-Sieberer U, Schlack R (2007) The German Health Interview and Examination Survey for Children and Adolescents (KiGGS): risks and resources for the mental development of children and adolescents. Bundesgesundheitsblatt Gesundheitsforschung Gesundheitsschutz 50(5-6):800-809. doi:10.1007/s00103-007-0243-5

Erhart $\mathrm{M}$ et al (2009) Measuring mental health and well-being of school-children in 15 European countries using the KIDSCREEN-10 Index. Int J Public Health 54(Suppl 2):160-166. doi:10.1007/s00038-009-5407-7

Eymann A, Busaniche J, Llera J, Cunto CD, Wahren C (2009) Impact of divorce on the quality of life in school-age children. J Pediatria 85(6):547-552

Fagnano M, Bayer AL, Isensee CA, Hernandez T, Halterman JS (2011) Nocturnal asthma symptoms and poor sleep quality among urban school children with asthma. Acad Pediatr 11(6): 493-499. doi:10.1016/j.acap.2011.05.006

Genuneit J et al (2011) The GABRIEL Advanced Surveys: study design, participation and evaluation of bias. Paediatr Perinat Ep 25(5):436-447. doi:10.1111/j.1365-3016.2011.01223.x

Giannakopoulos G et al (2009) Adolescents' wellbeing and functioning: relationships with parents' subjective general physical and mental health. Health Qual Life Outcomes 7:100. doi:10.1186/ 1477-7525-7-100

Haraldstad K, Christophersen KA, Eide H, Nativg GK, Helseth S (2011) Predictors of health-related quality of life in a sample of children and adolescents: a school survey. J Clin Nurs 20(21-22):3048-3056. doi:10.1111/j.1365-2702.2010.03693.x

Hysing M, Sivertsen B, Stormark KM, Elgen I, Lundervold AJ (2009) Sleep in children with chronic illness, and the relation to emotional and behavioral problems: a population-based study. J Pediatr Psychol 34(6):665-670. doi:10.1093/jpepsy/jsn095 
Illi S et al (2011) Protection from childhood asthma and allergy in Alpine farm environments-The GABRIEL Advanced Studies. J Allergy Clin Immun (submitted)

Illi S et al (2012) Protection from childhood asthma and allergy in Alpine farm environments: the GABRIEL Advanced Studies. J Allergy Clin Immunol 129(6):1470-1477 10.1016/j.jaci.2012. 03.013

Lemola $S$ et al (2010) Sleep quantity, quality and optimism in children. J Sleep Res 20:12-20

Luntamo T, Sourander A, Santalahti P, Aromaa M, Helenius H (2011) Prevalence changes of pain, sleep problems and fatigue among 8-year-old children: years 1989, 1999, and 2005. J Pediatr Psychol. doi:10.1093/jpepsy/jsr091

Michel G, Bisegger C, Fuhr DC, Abel T (2009) Age and gender differences in health-related quality of life of children and adolescents in Europe: a multilevel analysis. Qual Life Res 18(9):1147-1157. doi:10.1007/s11136-009-9538-3

Nunnally JC, Bernstein IH (eds) (1994) Psychometric theory. McGraw-Hill, New York

Petersen-Ewert C, Erhart M, Ravens-Sieberer U (2011) Assessing health-related quality of life in European children and adolescents. Neurosci Biobehav Rev 35(8):1752-1756. doi:10.1016/ j.neubiorev.2011.02.012

Ravens-Sieberer U (2004) Description of the KIDSCREEN instruments. http://wwwkidscreenorg/english. Accessed 07.07. 2012

Ravens-Sieberer U, Bullinger M (2000) KINDL-R Manual. http://kindl.org/cms/wp-content/uploads/2009/11/ManEnglish.pdf Accessed 22.06. 2011

Ravens-Sieberer U, Gortler E, Bullinger M (2000) Subjective health and health behavior of children and adolescents-a survey of Hamburg students within the scope of school medical examination. Gesundheitswesen 62(3):148-155. doi:10.1055/s-200010487
Ravens-Sieberer U, Ellert U, Erhart M (2007) Gesundheitsbezogene Lebensqualität von Kindern und Jugendlichen in Deutschland. Bundesgesundheitsblatt Gesundheitsforschung Gesundheitsschutz 50(5-6):810-818

Ravens-Sieberer U, Erhart M, Gosch A, Wille N (2008) Mental health of children and adolescents in 12 European countries-results from the European KIDSCREEN study. Clin Psychol Psychother 15(3):154-163

Silva CH, Silva TE, Morales NM, Fernandes KP, Pinto RM (2009) Quality of life in children and adolescents with allergic rhinitis. Braz J Otorhinolaryngol 75(5):642-649. doi:S1808-8694200 9000500005

Stocklin L, Loss G, von Mutius E, Genuneit J, Horak E, BraunFahrlander C (2012) Health-related quality of life does not explain the protective effect of farming on allergies. Pediatr Allergy Immunol. doi:10.1111/j.1399-3038.2012.01305.x

Sung V, Hiscock H, Sciberras E, Efron D (2008) Sleep problems in children with attention-deficit/hyperactivity disorder-prevalence and the effect on the child and family. Arch Pediat Adol Med 162(4):336-342

Tsiros MD et al (2009) Health-related quality of life in obese children and adolescents. Int J Obes (Lond) 33(4):387-400. doi:10.1038/ ijo.2009.42

UNICEF (2007) An overview of child well-being in rich countries. Unicef Innocenti Report Card 7

von Mutius E, Vercelli D (2010) Farm living: effects on childhood asthma and allergy. Nat Rev Immunol 10(12):861-868. doi: $10.1038 /$ nri2871

WHO (2000) Obesity: preventing and managing the global epidemic. Report of a WHO consultation. World Health Organ Tech Rep Ser 894(i-xii):1-253

WHO (2003) WHO definition of health. http://wwwwhoint/about/ definition/en/printhtml. Accessed 12.06.2012 2012 